\title{
Repair of Nelgected Achilles Tendon Rupture with Monofilament Polypropylene Mesh: A Case Study of 12 Patients
}

\author{
by Robert Fridman, DPM, AACFAS ${ }^{1} \rrbracket$, Fred Rahimi, DPM, FACFAS ${ }^{2}$, Paul Lucas, DPM, \\ FACFAS $^{3}$, Rob Daugherty, DPM, AACFAS ${ }^{4}$, Heidi Hoffmann, DPM $^{5}$
}

The Foot \& Ankle Journal 1 (5): 2

The purpose of this study is to evaluate the effectiveness of polypropylene mesh as an alternative to autogenous grafts and/or tendon transfers for neglected Achilles tendon rupture. Twelve patients with neglected Achilles tendon rupture underwent surgical repair using monofilament polypropylene mesh graft from 1999-2003. The average follow-up was 1.5 years. All patients were placed in a non-weight bearing, below-knee cast for 3 weeks, followed by 3 weeks of partial weight bearing in walking boot. All patients healed uneventfully, with three patients complaining of mild pain, one of moderate pain, and five with stiffness that resolved with physical therapy. The adjunctive use of monofilament polypropylene mesh is an appropriate method for the treatment of neglected Achilles tendon ruptures.

Key words: Achilles Tendon Rupture, Achilles Tendon Repair, Marlex ${ }^{\circledR}$ Mesh

Accepted: April 1, 2008

Published: May 1, 2008

This is an Open Access article distributed under the terms of the Creative Commons Attribution License. It permits unrestricted use, distribution, and reproduction in any medium, provided the original work is properly cited. @The Foot \& Ankle Journal (www.faoj.org)

Degeneration, tendon contracture, and a high rerupture rate are frequent sources of failure in nonoperative treatment of neglected Achilles tendon ruptures. ${ }^{1} \quad$ Bosworth previously noted that retraction of the gastrocnemius-soleus complex may occur within three days of injury, making reapproximation of the tendon ends difficult. ${ }^{2}$ Current clinical practice supports surgical repair of the tendon in this condition. End-to-end ${ }^{3}$, percutaneous ${ }^{4}$ and limited-open repairs ${ }^{5}$ may not be as effective in neglected ruptures due to excessive tendon contracture and degeneration of the tendon ends.

Address correspondence to: Robert Fridman, DPM, AACFAS, Department of Orthopaedics, New York-Presbyterian Hospital, University Hospitals of Columbia and Cornell, New York, NY.

\footnotetext{
${ }^{1}$ Private Practice, Foot Associates of New York, New York, NY.

${ }^{2}$ Fahey Medical Center, Des Plaines, IL.

${ }^{3}$ Alexian Brothers Medical Center, Hoffman Estates, IL.

${ }^{4}$ Private Practice, Daugherty Foot and Ankle Clinic, Cape Girardeau, MI.
}

${ }^{5}$ Private Practice, Northwest Suburban Podiatry, Arlington Heights, IL.
Therefore, tendon augmentation is routinely employed in cases of neglected rupture. The flexor hallucis longus tendon is most commonly used to augment reconstruction. ${ }^{6,7,8}$ Mann and others described using the tendon of the flexor digitorum longus as a graft. ${ }^{9}$ Fascia lata, ${ }^{10}$ peroneus brevis, ${ }^{11}$ gracilis, ${ }^{12}$ and plantaris ${ }^{13}$ tendon grafts have also been described in the literature.

Synthetic grafts may also be used to augment the surgical repair in situations where surrounding autogenous tissues are weak or unable to span the defect. The advantages of synthetic grafts over autogenous grafts include absent donor site morbidity and unlimited material available for sizable defects. 


\begin{tabular}{|c|c|c|c|c|c|c|}
\hline Patient & Age & Gender & Side & Follow Up & Injury to Treatment & Previous Treatment \\
\hline 1 & 57 & $\mathrm{~F}$ & Left & 1 year & 10 days & None \\
\hline 2 & 58 & $\mathrm{~F}$ & Right & 4 years & 4 weeks & Cast, boot \\
\hline 3 & 31 & M & Left & 1.5 years & 8 weeks & Cast, NSAIDS \\
\hline 4 & 70 & $\mathrm{~F}$ & Right & 2 years & unknown & None \\
\hline 5 & 39 & $\mathrm{~F}$ & Right & 4 years & unknown & Cast boot \\
\hline 6 & 60 & $\mathrm{~F}$ & Left & 4 years & unknown & Cast boot \\
\hline 7 & 66 & $\mathrm{~F}$ & Right & 6 months & unknown & None \\
\hline 8 & 60 & $\mathrm{~F}$ & Left & 1 year & 6 months & Cast, NSAIDS, Steroid Injections \\
\hline 9 & 69 & $\mathrm{~F}$ & Right & 4 years & unknown & None \\
\hline 10 & 38 & $\mathrm{M}$ & Left & 6 months & 1 month & Cast boot, NSAIDS \\
\hline 11 & 45 & M & Left & 6 months & unknown & Cast \\
\hline 12 & 38 & M & Left & 1.5 years & 2 weeks & Cast boot \\
\hline
\end{tabular}

TABLE 1 Demographics of 12 patients with neglected Achilles tendon rupture.

A distinct disadvantage of synthetic grafts is possible foreign body reaction after implantation. Dacron ${ }^{\circledR}$ vascular graft, ${ }^{14}$ carbon fiber composites, ${ }^{15}$ collagen tendon prosthesis, ${ }^{16}$ and GraftJacket $\mathbb{R}^{17}$ have all been described as alternatives to autogenous grafts. Ozaki, et al, reported that polypropylene mesh had little to no tissue reaction when implanted during rotator cuff repair ${ }^{18}$ and subsequently used this material for repair of Achilles tendon with satisfactory results. ${ }^{19}$ This case study reports on a series of neglected Achilles ruptures repaired with Marlex (B) polypropylene mesh.

\section{Materials and Methods}

Twelve patients with neglected Achilles tendon rupture were treated surgically by the same surgeon using Marlex ${ }^{\circledR}$ polypropylene mesh (Davol Inc., Rhode Island, USA) as described by Ozaki, et al. The diagnosis of neglected Achilles tendon rupture was based on history, clinical and MRI findings.
Neglected tears were defined as a closed rupture of 10 or more days duration without previous surgical treatment for the affected tendon. MRI findings were all indicitive for complete rupture of the Achilles tendon with fatty degeneration. (Fig.1) The average patient age was 52.5 years (range $=31$ to 70 years). There were 8 males and 4 females included in the study, with an average follow-up period of 1.5 years (range $=0.5-4$ years). Table 1 summarizes the demographic data. Patients were either contacted by telephone or interviewed in the clinic. A modified VISA-A Questionnaire was used for clinical evaluation. ${ }^{20}$ (Table 2)

\section{Surgical Procedure}

The procedure is performed under general anesthesia with a pneumatic thigh tourniquet. Both lower extremities are prepped and draped, so as to have an appropriate reference point when tensioning the repaired tendon. Prophylactic antibiotics are given prior to inflating the tourniquet. The patient is positioned prone and local anesthetic is infiltrated into the surgical site. A posteromedial incision is made along the Achilles tendon extending proximally and distally past the defect (Fig. 2). 


\section{Pain}

None

Mild, no limited recreational activities

Moderate, limited recreational, but not daily activities

Severe, limited recreational and daily activities

\section{Stiffness}

None

Mild, occasional, no limited recreational activities

Moderate, limited recreational, but not daily activities

Severe, limited recreational and daily activities

\section{Muscle Weakness (subjective)}

None

Mild, occasional, no limited recreational activities

Moderate, limited recreational, but not daily activities

Severe, limited recreational and daily activities

\section{Footwear Restrictions}

\section{None}

Mild, most shoes tolerated

Moderate, unable to tolerate fashionable shoes, modified shoes tolerated

Severe, all shoes cause irritation and/or discomfort

\section{Work Restrictions}

None

Mild, need to rest after a half day at work

Moderate, need to rest after one hour

Severe, sitting job only

Overall Result (subjective)

Very Satisfied

Satisfied with minor reservations

Satisfied with major reservations

Dissatisfied

TABLE 2 The modified VISA-A (Victorian Institute of Sport Assessment-Achilles) Questionnaire. 


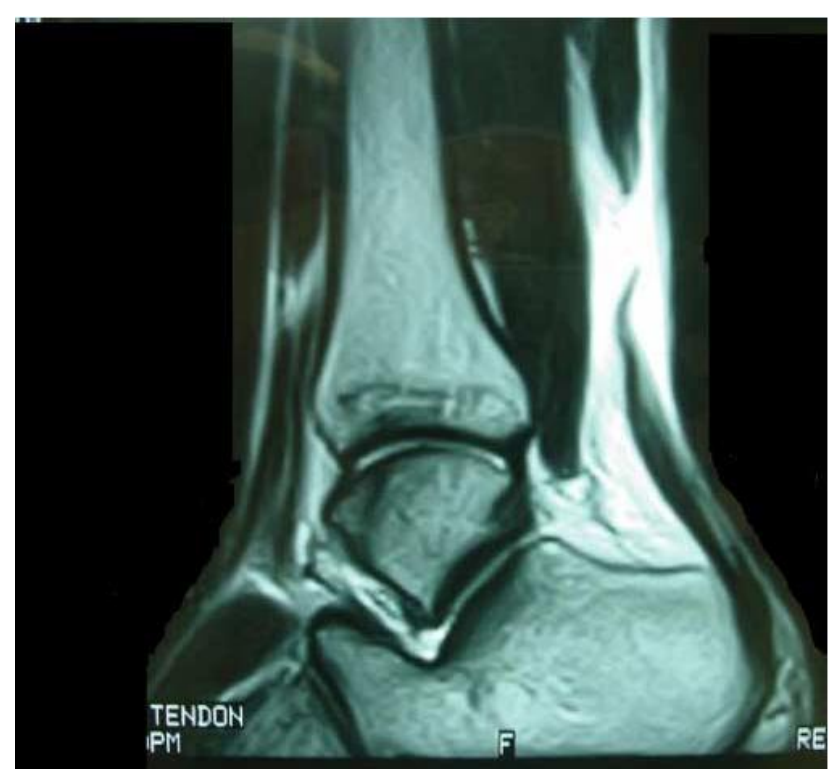

Figure $1 \mathrm{MRI}$ of neglected rupture of Achilles tendon shows significant gapping and degeneration of tendon ends.

The sural nerve is retracted laterally, and the paratenon is incised and tagged for later closure. The ruptured ends of the tendon are identified, and fibrotic and/or degenerated tendon is excised (Fig. 3). The tendon ends are prepared for insertion into the mesh graft by incising the tendon $2-3 \mathrm{~cm}$ in the frontal plane. The mesh is prepared by tri-folding it to a slightly smaller width than the tendon itself. The folds are secured with 3-0 non-absorbable suture (Fig. 4). To assess the length of graft, the gastrocnemiussoleus complex is pulled distally and then compared to the resting tension of the contralateral limb. The mesh is then measured and cut to fit the defect. The mesh is held in place with heavy non-absorbable suture, securing all knots anteriorly to prevent scarring and stenosis with the underlying superficial fascia and skin. The proximal portion is secured first (Fig.5), which allows for easier tensioning adjustments prior to securing the distal end.

A portion of the plantaris tendon is resected and fanned out to cover the anterior and posterior portion of the graft, and is secured using 3-0 nonabsorbable suture (Fig. 6).

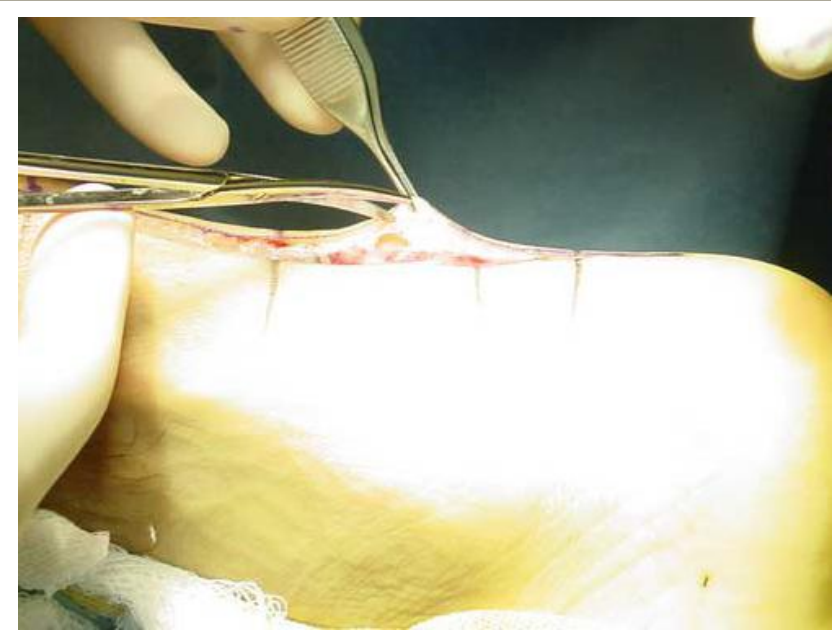

Figure 2 A posteromedial incision is made along the Achilles tendon extending proximally and distally past the defect.

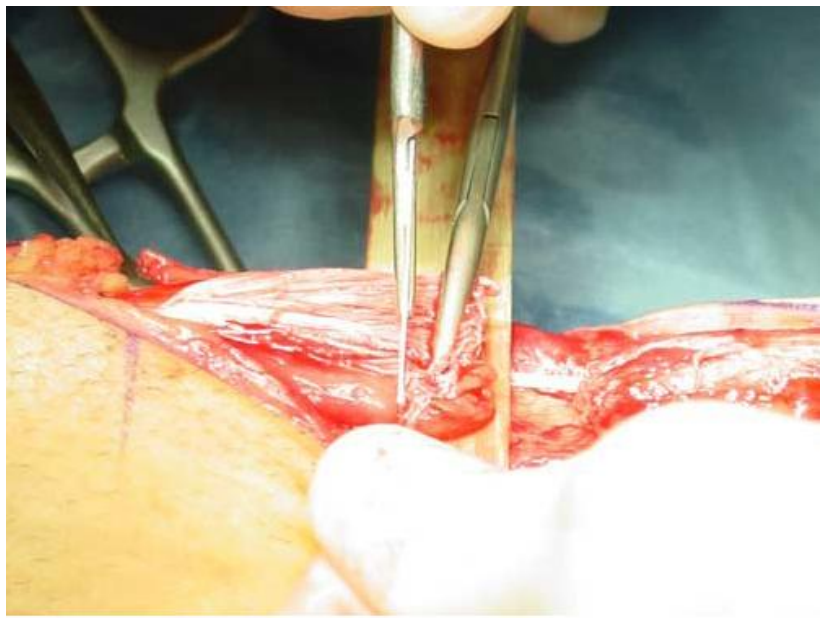

Figure 3 The ruptured ends of the tendon are identified and degenerated tendon is removed.

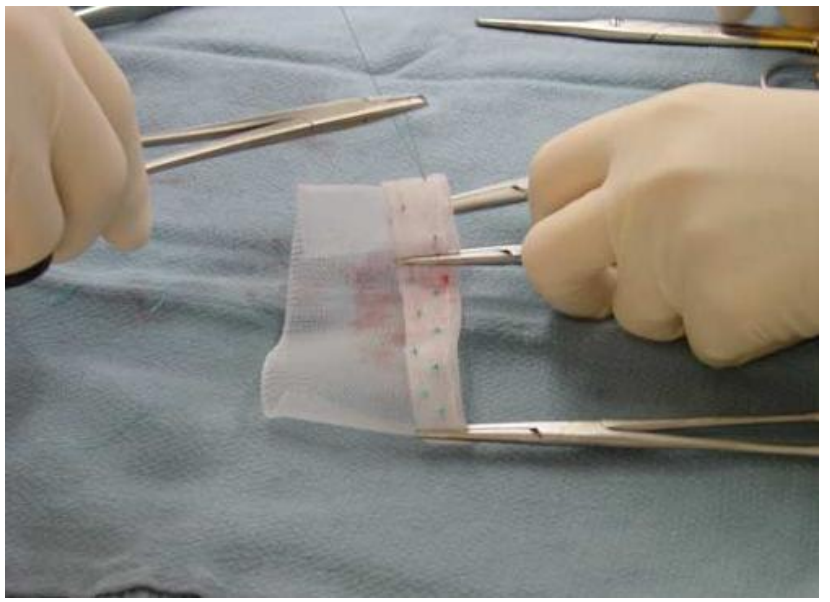

Figure 4 The mesh is prepared by folding it 3 times to a slightly smaller width than the tendon itself. The folds are secured with 3-0 nonabsorbable suture. 


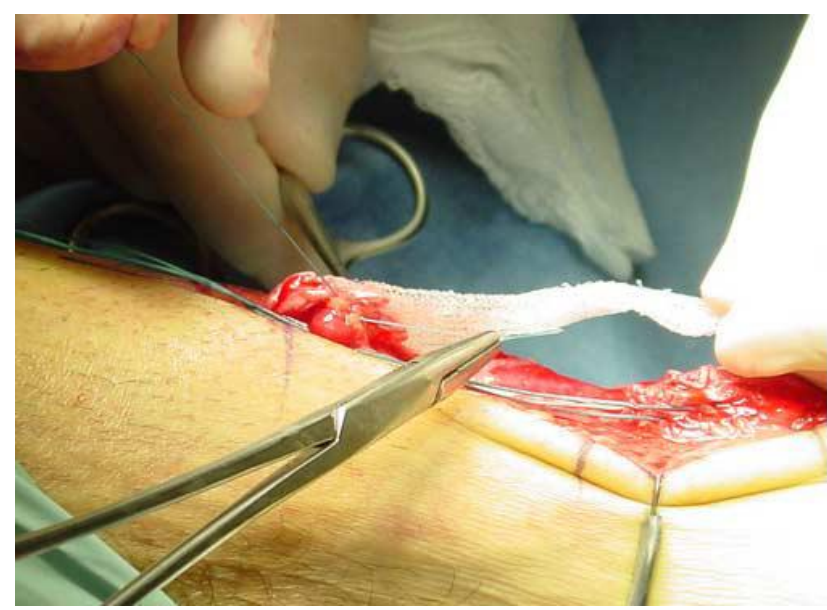

Figure 5 The proximal portion of the mesh-tendon interface is first secured.

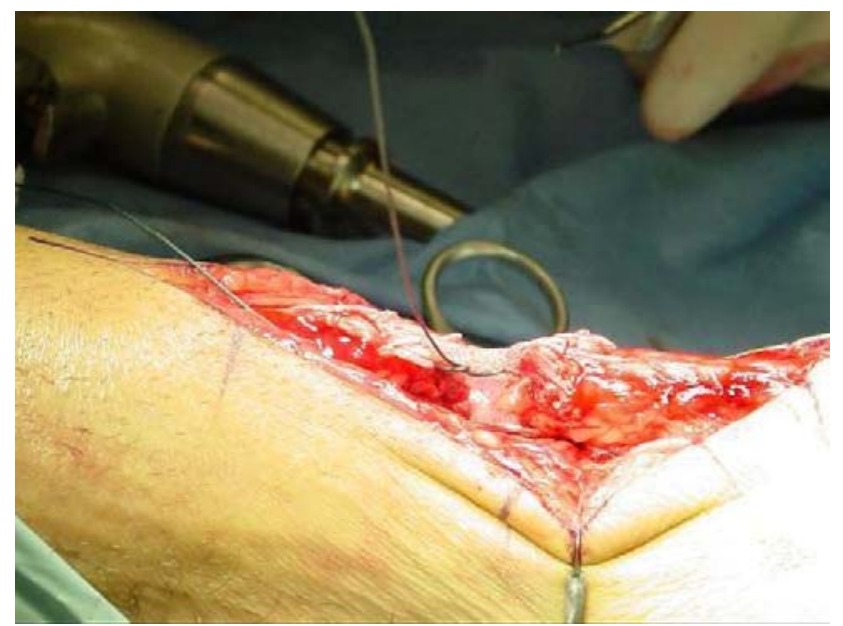

Figure 6 A portion of the plantaris tendon is resected and fanned out to cover the anterior and posterior portion of the graft and is secured.

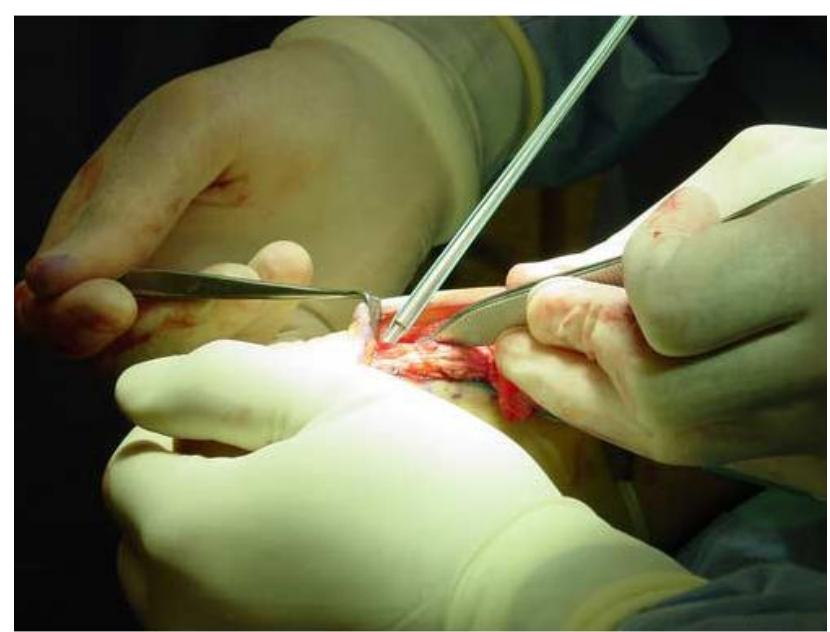

Figure 7 Bone anchors secure the repaired tendon to the calcaneus.

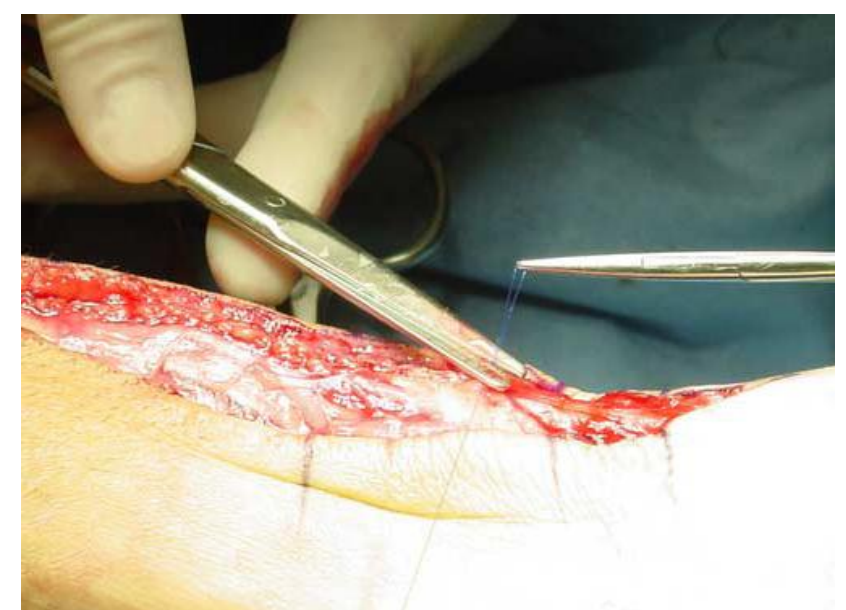

Figure 8 The paratenon is reapproximated.

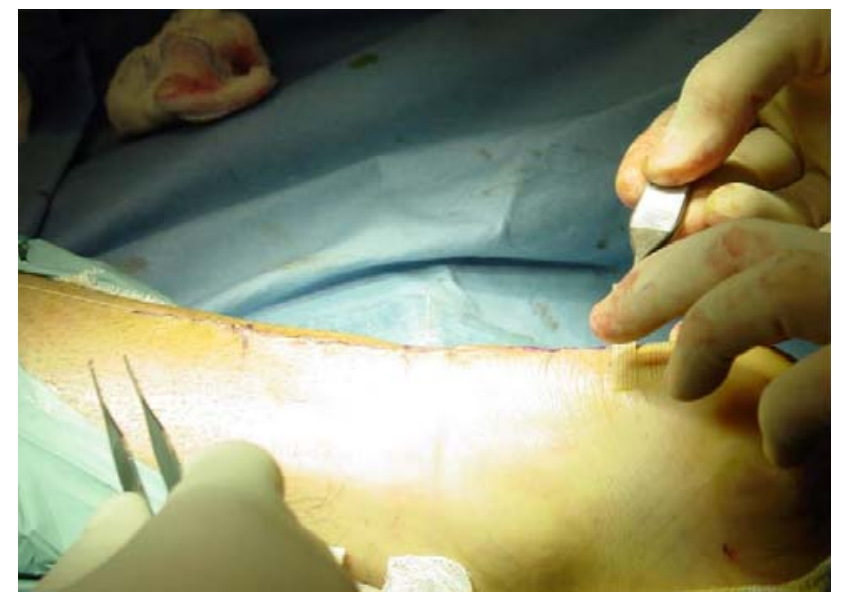

Figure 9 Absorbable suture is used for closure and surgical strips are placed across the surgery site.

The tendon and graft are reinforced with calcaneal bone anchors inserted medially and laterally (Fig. 7). The anchor sutures are then braided along the sides of the tendon creating a finger-trap stitch. The paratenon is repaired with an interlocking baseball stitch and the skin is reapproximated using 5.0 absorbable suture. (Figs. $8,9)$

All patients were placed in a non-weight bearing, short leg cast in gravity equinus for 3 weeks, and then advanced to a non-weight bearing walking boot with passive range of motion exercises for an additional 3 weeks. Progressive weight bearing with active physical therapy was initiated postoperatively at 6 weeks.

(C) The Foot \& Ankle Journal, 2008 


\begin{tabular}{|c|c|c|c|c|c|}
\hline Patient & Stiffness & Muscle Weakness & Footwear Restrictions & Work Restrictions & Overall Result \\
\hline 1 None & Mild & None & None & None & Very Satisfied \\
\hline 2 None & Mild & Mild & Mild & None & Very Satisfied \\
\hline 3 None & None & None & None & None & Very Satisfied \\
\hline 4 None & None & None & None & None & Very Satisfied \\
\hline 5 Mild & None & None & Mild & None & Very Satisfied \\
\hline 6 Mild & None & None & None & None & Very Satisfied \\
\hline 7 None & None & None & None & None & Very Satisfied \\
\hline 8 None & None & None & None & None & Very Satisfied \\
\hline 9 None & None & None & None & None & Very Satisfied \\
\hline 10 None & Mild & None & None & None & Satisfied \\
\hline 11 Mild & Mild & None & Mild & None & Satisfied \\
\hline 12 Moderate & Mild & Mild & Mild & None & Satisfied \\
\hline
\end{tabular}

TABLE 3 Data Results.

\section{Results}

The average time for follow-up was 1.5 years (range $0.5-4$ years; mean $=2$ years; standard deviation 1.515; median 1.5 years; 25 th percentile $=0.75$ years; $75^{\text {th }}$ percentile $=4$ years). There were no cases of foreign body reaction following implantation of the mesh graft. All patients were able to return to work or to their level of activity before the injury. Of the twelve patients involved in the study, eight related no pain at the time of the interview.

Three patients related mild pain. One patient presented to the surgeon five months after surgery complaining of moderate pain at the operative site, and stated that he heard a "pop" when ambulating and began to experience pain at the surgical site. This patient was immobilized in a non-weightbearing walking boot with crutches and follow-up MRI showed evidence of diffuse thickening at the site of the repair with no evidence of a recurrent tear. He then returned to pre-operative activities of daily living without incident. Five patients related mild ankle joint stiffness upon waking in the morning. Two patients complained of mild weakness to the calf muscle.
Four patients stated that they were limited in their shoe gear, with one patient stating that she was no longer able to wear high heel shoes. All patients were satisfied with the overall results of the procedure. (Table 3)

\section{Discussion}

A number of surgical techniques have been described for the repair of neglected Achilles tendon ruptures. Autogenous grafts in the form of local tendons or free fascia may be used when the donor tissue is healthy and where the gaps are manageable. Synthetics grafts are useful when autogenous grafts cannot be used.

Lieberman, et al, ${ }^{14}$ described repair of Achilles tendon ruptures with Dacron ${ }^{\circledR}$ vascular graft in 7 patients, with a follow-up of ten to 38 months. The graft was woven from distal to proximal and across the rupture in a Bunnell-type fashion, and the patients were immobilized in a short-leg cast for two weeks and then fitted with a posterior fiberglass splint. 
Patients were allowed to return to their normal level of activity approximately five months after surgery. There was no incidence of re-rupture, wound infection, or skin adhesion. All of the patients had normal gait, normal range of motion of the ankle, and had returned to their pre-injury level of activity. Two patients noted weakness in the injured leg and two years after the repair; however, their activity levels had not been altered. Another patient complained of tightness in the tendon area and discomfort after a significant amount of exercise.

Parsons, et $\mathrm{al}^{15}{ }^{15}$ described repair of Achilles tendon using a composite carbon implant in 48 patients/51 procedures with an average follow-up of 2.1 years. Three cohort groups were observed on a temporal basis and quantitatively evaluated at 1 year $(\mathrm{N}=29), 18$ months $(\mathrm{N}=22)$, and 2 years $(\mathrm{N}=20)$, respectively. These three groups demonstrated continuous improvement during the first postoperative year, with $86 \%$ having a good to excellent result. A high level of function was maintained throughout the second year.

Lee ${ }^{17}$ described a case-report using GraftJacket ${ }^{\circledR}$ for augmentation of a gastrocnemius recession repair in a chronic Achilles rupture. The augmentation obviated the need for tendon transfer or free tendon graft, and early return to activity and good plantarflexion strength was noted postoperatively.

This series reports on 12 patients who were repaired using Marlex ${ }^{\circledR}$ polypropylene mesh. This material has been extensively used in general and cardiovascular surgery with predictable results. Hosey, et al, studied the Marlex ${ }^{\circledR}$ tendon complex in rabbits and reported that it had similar physical properties to a normal tendo Achilles. ${ }^{20}$ There was no reported incidence of foreign body reaction. The potential risk of donor site morbidity was eliminated through use of a synthetic graft. All patients were satisfied or very satisfied with their surgical outcome. Ozaki ${ }^{19}$ and Choskey $^{22}$ reported findings that were similar to those in our set.
There are a number of limitations in this study. The sample size is small, and our results are compared to historical controls, which inherently introduces bias between the two groups. Additionally, we did not consider any independent variables, such as weight or length of the tendon defect, which may have added confounders or bias to the overall outcome of the study.

The VISA-A (Victorian Institute of Sport Assessment-Achilles) questionnaire provides a valid and reliable index of severity of Achilles tendinopathy. ${ }^{20}$ It was modified in this study to include questions about return to work and footwear restrictions. Additionally, it qualifies VISA-A pain, stiffness, and weakness score of 0 as none, $1-3$ as mild, 4-6 as moderate, and $7-10$ as severe. This modification may alter the operating characteristics of the questionnaire, however, it is quite unlikely.

In conclusion, the results demonstrated above suggest that polypropylene mesh graft is an effective alternative to autogenous grafts and/or tendon transfers in the treatment of neglected Achilles tendon rupture.

This investigation was not funded by any commercial or other outside agency or corporation. The investigators do not have any potential conflicts of interest, actual or perceived, to this investigation. 


\section{References}

1. Lo, IK; Kirkley, A; Nonweiler, B; Kumbhare, DA. Operative versus non-operative treatment of acute Achilles tendon ruptures: a quantitative review. Clin J Sport Med. Jul;7(3):207-11, 1997.

2. Bosworth DM. Repair of Defects in the Tendo Achilles. J Bone Joint Surg Am. Jan;38-A(1):111-4, 1956.

3. Porter DA, Mannarino FP, Snead D, Gabel SJ, Ostrowski M.Primary repair without augmentation for early neglected Achilles tendon ruptures in the recreational athlete. Foot Ankle Int. Sep;18(9):557-64, 1997.

4. Ma GW, Griffith TG. Percutaneous repair of acute closed ruptured achilles tendon: a new technique. Clin Orthop Relat Res. Oct;(128):247-55, 1977.

5. Assal M, Jung M, Stern R, Rippstein P, Delmi M, Hoffmeyer P. Limited open repair of Achilles tendon ruptures: a technique with a new instrument and findings of a prospective multicenter study.

J Bone Joint Surg Am. Feb;84-A(2):161-70, 2002.

6. Wapner, KL; Pavlock, GS; Hecht, PJ; Naselli, F; Walther, R. Repair of chronic Achilles tendon rupture with flexor hallucis longus tendon transfer. Foot Ankle. Oct; 14(8):443-9, 1993.

7. Hansen, ST: Transfer of the flexor hallucis longus to the heel cord. In: ST Hansen, ed, Functional Reconstruction of the Foot and Ankle, Philadelphia, Lippincott, pp. 425-429, 2000.

8. Tashjian RZ, Hur J, Sullivan RJ, Campbell JT, DiGiovanni CW. Flexor hallucis longus transfer for repair of chronic achilles tendinopathy. Foot Ankle Int. Sep;24(9):673-6, 2003.

9. Mann RA, Holmes GB Jr, Seale KS, Collins DN. Chronic rupture of the Achilles tendon: a new technique of repair. J Bone Joint Surg Am. Feb;73(2):214-9, 1991.

10. Dabernig J, Shilov B, Schumacher O, Lenz C, Dabernig W, Schaff J. Functional reconstruction of Achilles tendon defects combined with overlaying skin defects using a free tensor fasciae latae flap.J Plast Reconstr Aesthet Surg. 59(2):142-7, 2006.

11. Miskulin M, Miskulin A, Klobucar H, Kuvalja S. Neglected rupture of the Achilles tendon treated with peroneus brevis transfer: a functional assessment of 5 cases.J Foot Ankle Surg. Jan-Feb;44(1):49-56, 2005.

12. Maffulli N, Leadbetter WB. Free gracilis tendon graft in neglected tears of the Achilles tendon. Clin J Sport Med. Mar;15(2):56-61, 2005.

13. Schedl R, Fasol P. Achilles tendon repair with the plantaris tendon compared with repair using polyglycol threads. J Trauma. Mar;19(3):189-94, 1979.

14. Lieberman JR, Lozman J, Czajka J, Dougherty J. Repair of Achilles tendon ruptures with Dacron vascular graft. Clin Orthop Relat Res.Sep;(234):204-8, 1988.

15. Parsons JR, Weiss AB, Schenk RS, Alexander H, Pavlisko F. Long-term follow-up of Achilles tendon repair with an absorbable polymer carbon fiber composite. Foot Ankle. Feb;9(4):179-84, 1989.

16. Kato YP, Dunn MG, Zawadsky JP, Tria AJ, Silver FH. Regeneration of Achilles tendon with a collagen tendon prosthesis. Results of a one-year implantation study. J Bone Joint Surg Am. Apr;73(4):561-74, 1991.

17. Lee MS. GraftJacket augmentation of chronic Achilles tendon ruptures. Orthopedics. Jan;27(1 Suppl):s151-3, 2004.

18. Ozaki J, Fujimoto S, Masuhara K, Tamai S, Yoshimoto S. Reconstruction of chronic massive rotator cuff tears with synthetic materials. Clin Orthop Relat Res. Jan;(202):173-83, 1986.

19. Ozaki J, Fujiki J, Sugimoto K, Tamai S, Masuhara K. Reconstruction of neglected Achilles tendon rupture with Marlex ${ }^{\circledR}$ mesh. Clin Orthop Relat Res. Jan;(238):204-8, 1989.

20. Robinson JM, Cook JL, Purdam C, Visentini PJ, Ross J, Maffulli N, Taunton JE, Khan KM; Victorian Institute Of Sport Tendon Study Group. The VISA-A questionnaire: a valid and reliable index of the clinical severity of Achilles tendinopathy. Br J Sports Med. Oct;35(5):335-41, 2001.

21. Hosey G, Kowalchick E, Tesoro D, Balazsy J, Klocek J, Pederson B, Wertheimer SJ. Comparison of the mechanical and histologic properties of Achilles tendons in New Zealand white rabbits secondarily repaired with Marlex ${ }^{\circledR}$ mesh. J Foot Surg. May-Jun;30(3):214-33, 1991.

22. Choksey A, Soonawalla D, Murray J. Repair of neglected Achilles tendon ruptures with Marlex ${ }^{\circledR}$ mesh. Injury.

Apr;27(3):215-7, 1996. 